\title{
Malignant hyperthermia and the clean machine
}

Following use with halothane, ten anaesthestic machines were sampled using infrared analysis for halothane contamination. Baseline measurements of halothane were made in the room and at the machine's common gas outlet. Five per cent halothane with four litres per minute oxygen flow was delivered for ten minutes into a scavenged breathing circuit. Halothane was then discontinued, an oxygen flow rate of 12 litres per minute was begun, and continuous measurements were made until the halothane concentration became undetectable. Baseline measurements of the rooms and anaesthestic machines ranged from 0 to 0.8 parts per million. Following the oxygen flow, the halothane concentration decreased to undetectable levels within six minutes in all ten machines.

Malignant hyperthermia (MH) is a pharmacogenetic disorder characterized by acute hypermetabolic reactions in muscles in response to the triggering effect of certain anaesthetic agents. The known triggering agents are potent inhalational anaesthetic vapours and succinylcholine. The recommended intraoperative management of MH-susceptible patients includes avoidance of triggering agents, replacement of the carbon dioxide absorbent and all rubber and plastic tubing, and ideally changing the anaesthestic machine for one never used with volatile agents. ' Replacement of absorbent and hoses is recommended because of the inhalational agents' solubility in rubber, plastic, and possibly carbon dioxide absorbant. ${ }^{2,3}$ The American Society of Anesthesiologists Anesthesia

\section{Key words}

ANAESTHETICS, VOLATILE: halothane; EQUIPMENT: anaesthetic machines; HYPERTHERMIA: malignant.

From the Department of Anaesthesia, University of Pennsylvania, Department of Anesthesia and Critical Care, Children's Hospital of Philadelphia, 34th and Civic Center Blvd, Philadelphia, PA 19104.

Address correspondence to: Dr. T. McGraw, Assistant Professor of Clinical Anesthesia and Pediatrics, University of Cincinnati, Children's Hospital Medical Center, Elland and Bethesda Avenues, Cincinnati, OH 45229 USA.
Technical Bulletin's recommendations for the management of patients known to be MH-susceptible include: "Clean anesthesia machine and delivery circuit. Flow oxygen through machine for 12 hours preop. Remove halogenated agents from machine. Fresh $\mathrm{CO}_{2}$ absorbent in cannister or a non-rebreathing system."

In our hospital, MH-susceptible patients are scheduled as the first patient in the operating room so that we can conform with the recommendation of flushing the machine for 12 hours before induction of anaesthesia. However, we felt that this may not be necessary if the machines could be flushed free of inhalational agents in a shorter time.

\section{Methods}

We studied all ten Ohmeda Modulus II anaesthesive machines in our operating rooms. Measurements were made at the end of a regular working day during which halothane had been administered. The time interval from a machine's last use with a patient ranged from ten minutes to three hours.

A Miran-103 portable gas analyzer was used to measure halothane concentrations. This infrared analyzer is supplied with fixed infrared filtres which enable the spectrometer to measure absorption at one particular wavelength and thus identify and determine the concentration of one specific gas. A factory-calibrated halothane filtre and scale were used and parts per million of halothane were recorded from the metre readout. Accuracy of \pm five per cent and a sensitivity of approximately one part per million are reported by the manufacturer.

A pilot study using gas chromatography analysis after flushing the machines for ten minutes failed to detect halothane. Twenty samples were collected in appropriate metal containers and analyzed by a laboratory which regularly tests air samples for operating room pollution. Infrared analysis permitted on site analysis of rapid changes in halothane concentration which occur when the machine is flushed.

Prior to all measurements the gas analyzer was zeroed outside the operating room. Baseline measurements of halothane were made in the room and from the anaesthestic machine's common gas outlet prior to beginning study of each machine. Five per cent halothane with a 4 
TABLE Halothane washout

\begin{tabular}{llllll}
\hline \multicolumn{5}{c}{ Minules following halothane flow* } \\
\cline { 5 - 6 } & Baseline & 0 & 2 & 4 & 6 \\
\hline Mean halothane ppm (range) & Machine & & & & \\
& 0.1 & $>10$ & 0.7 & 0.2 & 0.0 \\
& $(0.0-0.7)$ & $($ all) & $(0.0-3.0)$ & $(0.0-0.9)$ & $($ all) \\
& Room & & & & \\
& 0.4 & 0.3 & & & 0.4 \\
& $(0.0-0.8)$ & $(0.0-0.6)$ & & $(0.0-1.0)$ \\
\hline
\end{tabular}

*Halothane $5 \%$ in oxygen at $4 \mathrm{~L} \cdot \mathrm{min}^{-1}$ for ten minutes. Measurements obtained during $12 \mathrm{~L} \cdot \mathrm{min}^{-1}$ flow of oxygen.

$L \cdot \min ^{-1}$ oxygen flow was then delivered for ten minutes into a scavenged breathing circuit. Halothane was discontinued by turning off the vaporizer (without removal). Then halothane measurements were made again of the room and of the anaesthestic machine's common gas outlet. An oxygen flow rate of $12 \mathrm{~L} \cdot \mathrm{min}^{-1}$ was begun and continuous measurements were made until the halothane concentration decreased to zero. The operating room halothane concentration was determined again at the termination of the study.

\section{Results}

Baseline measurements from the common gas outlet of the anaesthestic machine before beginning the study ranged from 0 to 0.7 parts per million with a mean of 0.1 parts per million. Room air pollution at the same time ranged from 0 to 0.8 parts per million with a mean of 0.4 parts per million. Immediately following ten minutes of five per cent halothane at a $4 \mathrm{~L} \cdot \mathrm{min}^{-1}$ flow rate, the concentration of halothane was greater than ten parts per million (beyond the scale) from all machines. Room air pollution at that time ranged from 0 to 0.6 parts per million. With the vaporizers turned off and an oxygen flow rate of $12 \mathrm{~L} \cdot \mathrm{min}^{-1}$, the halothane concentrations began to decrease below ten parts per million within two minutes, and reached zero by six minutes with all ten machines (Table). Room air pollution at six minutes ranged from 0 to 1.0 parts per million with a mean of 0.4 parts per million.

\section{Discussion}

Previous studies of halothane washout have yielded similar results to ours. Samulska et al., ${ }^{5}$ using gas chromatography, were unable to detect halothane after flushing with oxygen at $6 \mathrm{~L} \cdot \mathrm{min}^{-1}$ for 12 minutes. Ritchie et al., ${ }^{7}$ using mass spectrometry to measure halothane washout in a variety of machines, found levels less than 0.5 parts per million after about ten minutes.
Neither of these studies employed Ohmeda machines. A recent study by Beeby and Sessler, ${ }^{3}$ using mass spectrometry to investigate a single Ohmeda machine, measured less than one part per million halothane after five minutes of $10 \mathrm{~L} \cdot \mathrm{min}^{-1}$ oxygen flush, when measurements were taken at the fresh gas outlet of the machine.

Halothane concentrations at the common gas outlet of every machine in our study decreased below the baseline room concentrations within about four minutes. These levels were below those recommended by the National Institute of Occupational Safety and Health (NIOSH) for a scavenged operating room: two parts per million balothane when diluted in oxygen, and 0.5 parts per million when diluted in oxygen/nitrous oxide. ${ }^{6}$

When anaesthetizing MH-susceptible individuals, current practices include using anaesthetic machines never exposed to potent inhalational agents, or removing all vaporizers and flushing anaesthestic machines for extended periods before use. Clinical data to support the ASA technical bulletin's recommendation for a 12-hour flush is lacking. While it is true that Ritchie et al. ${ }^{7}$ found 0.02 parts per million after 12 hours of flushing in some anaesthestic machines, this level is far below the expected ambient room air levels. Indeed, we know of no reports implicating ambient room air potent inhalational agents as triggers for malignant hyperthermia. While no "minimum triggering level" has been defined in man, it would be reasonable to assume this level to be greater than those recommended by NIOSH.

When flushing anaesthetic machines, vaporizers should be removed because some types, when coupled with certain mounting systems, continue to contaminate the gas flow when turned off. ${ }^{7}$ The other recommended practices are costly, time-consuming and inconvenient. We submit that a safe alternative to these practices, at least with the Ohmeda Modulus II machines, would be to remove the vaporizers from the anaesthetic machines, flush the machines with oxygen at high flow for 15 minutes, and to use circuit tubing, gas outlet and carbon 
dioxide absorbent never exposed to potent inhalational agents.

\section{References}

1 Relton JE. Anesthesia for elective surgery in patients susceptible to malignant hyperthermia. Int Anesthesiol Clin 1979; 17: 142-51.

2 Eger EI, Larson P, Severinghaus J. The solubility of halothane in rubber, soda lime, and various plastics. Anesthesiology 1962; 23: 356-9.

3 Beebe JJ, Sessler DI. Preparation of anesthesia machines for patients susceptible to malignant hyperthermia. Anesthesiology 1988; 69: 395-400.

4 Technical Bulletinf or Malignant Hyperthermia. Anesthesia Technical Bulletin No. 1. the American Society of Anesthesiologists Newsletter, November 1982.

5 Samulksa HM, Samala R, Noble WH. Unintended exposure to halothane in surgical patients: halothane washout studies. Can Anaesth Soc J 1972; 19: 35-41.

6 National Institute of Occupational Safety and Health: A Recommended Standard for Occupation Exposure to Waste Anesthetic Gases and Vapors. Washington, DC, US Government Printing Office, 1977, ppl-3.

7 Ritchie PA. Cheshire MA. Pearce NH. Decontamination of halothane from anaesthetic machines achieved by continuous flushing with oxygen. $\mathrm{Br} J$ Anaesth 1988; 60 : $859-63$.

\section{Résumé}

Nous avons analysé d l' infra-rouge, l'air ambiant et les gaz d la sortie de dix appareils d' anesthésie. Les mesures révélaient des concentrations d'halothane variant de 0 a 0.8 parties par million. Nous avons ensuite instille dans un système respiratoire muni d'un dispositif anti-pollution, cinq pour cent d' halothane avec quatre litres $\min ^{-1} d^{\prime}$ oxygène pendant dix minutes. Nous avons par la suite mesuré continuellement le niveau d' halothane pendant le lavage du système avec 12 litre $\mathrm{min}^{-1}$ d'oxygène. Avec les dix appareils, en moins de six minutes de lavage, la concentration d'halothane ếtait passée sous le seuil de détection. 